\title{
Absensi Online Untuk Ruang Kelas Berbasis Cloud Computing
}

\author{
Sri Listia Rosa ${ }^{1}$ dan Evizal Abdul Kadir ${ }^{2}$ \\ Teknik Informatika, Fakultas Teknik, Universitas Islam Riau ${ }^{1,2}$ \\ J1. Kaharuddin Nasution, Pekanbaru, Riau, Indonesia 28284 \\ srilistiarosa@eng.uir.ac.id ${ }^{1}$, evizal@eng.uir.ac.id ${ }^{2}$
}

\begin{tabular}{l}
\hline \hline Article Info \\
\hline History: \\
Dikirim 04 Juli 2019 \\
Direvisi 08 Juli 2019 \\
Diterima 23 Juli 2019 \\
\hline
\end{tabular}

\section{Kata Kunci:}

Absensi online

RFID

Cloud Computing

Database

\begin{abstract}
Abstrak
Kehadiran mahasiswa di dalam kelas adalah salah satu representasi penilaian diakhir kelas atau perkuliahan, beberapa mahasiswa menitipkan absen atau kehadirannya karena masih menggunakan sistem manual dengan tanda tangan di absen kehadiran. Selain itu, penggunaan sistem kehadiran secara manual kurang efektif karena sangat mudah di palsukan dan banyak adminsitrasi yang harus dilakukan, ditambah lagi penggunaan kertas yang lebih banyak. Penelitian ini membahas tentang sistem absensi otomatis secara online untuk mahamahasiswa dan dosen, di mana setiap mahamahasiswa sebelum masuk ke ruang kelas harus menempelkan kartu tanda mahamahasiswa mereka pada pembaca RFID dan sebelum keluar perlu menempelkan juga untuk bukti keluar. Toleransi waktu masuk dan keluar ditetapkan berdasarkan jadwal yang sudah diatur oleh Universitas, begitu juga untuk karyawan dan dosen, mirip dengan sistem untuk mahamahasiswa sebelum masuk kuliah setiap dosen harus menempelkan kartunya sebagai bukti masuk ke kelas dan juga untuk absen keluar. Data kehadiran mahamahasiswa dan dosen dengan nomor ruang kelas yang sudah diatur dikirim ke database untuk rekaman kehadiran mahamahasiswa dan juga pembayaran honorarium untuk dosen yang masuk. Rancangan sistem diuji di ruang kelas pada Fakultas Teknik, Universitas Islam Riau dengan jumlah mahasiswa sekitar 40 orang per kelas. Data yang dikumpulkan oleh pembaca RFID diteruskan ke server yang dikendalikan oleh teknologi informasi Universitas dan terhubung ke sistem penggajian di bagian keuangan. Sistem ini memberikan efektivitas dan efisiensi dalam administrasi, hasil dari pelaksanaan sistem ini maka tidak ada lagi pelaporan secara manual oleh petugas, sehingga dapat meringankan pekerjaaan karyawan untuk pencatatan kehadiran dosen di akhir bulan untuk pembayaran honorarium. Kelebihan lain dari sistem ini, dan juga mahamahasiswa dan dosen tidak dapat lagi meitipkan absensi kehadiran mereka dalam proses pembelajaran di kelas.

(C) This work is licensed under a Creative Commons AttributionShareAlike 4.0 International License.
\end{abstract}

\footnotetext{
Koresponden:

Sri Listia Rosa,

Program Studi Teknik Informatika, Fakultas Teknik

Universitas Islam Riau

Jl. Kaharuddin Nasution, Pekanbaru, Riau, Indonesia 28284

srilistiarosa@eng.uir.ac.id, evizal@eng.uir.ac.id
} 


\section{PENDAHULUAN}

Pengajaran di kelas adalah metode umum yang saat ini diterapkan oleh sebagian besar lembaga akademik termasuk di sekolah dan perguruan tinggi. Metode konvensional dengan menandatangani secara manual kehadiran dalam selembar kertas kemudian meneruskan ke beberapa orang di kelas sembari dosen melakukan pengajaran di kelas adalah metode yang sering dilakukan saat ini. Metode ini tidak diragukan lagi tetapi mahasiswa dengan mudah dapat menitipkan abesnnya dan berbuat curang dalam hal kehadiran mereka di kelas, di mana seorang mahasiswa dapat menandatangani untuk mahasiswa yang tidak hadir. Selain itu, formulir kehadiran sangat memungkinkan terjadinya kehilangan dan tercecer selama diedarkan dan pelaksanaan selama satu semester. Pendekatan yang lebih ketat khususnya untuk mencegah mahamahasiswa melakukan kecurangan tentang kehadiran mereka juga harus dilakukan, di mana biasanya seorang dosen memanggil nama dari setiap mahamahasiswa berdasarkan daftar nama dan memvalidasi kehadiranya. Cara manual untuk absensi mahamahasiswa ini telah terbukti tetapi sulit untuk dilaksankan dan memakan waktu untuk memeriksa setiap mahasiswa. Terkadang mahasiswa yang dikonfirmasi tidak merespons, perhitungan kehadiran terkonsolidasi adalah tugas utama lain yang dapat menyebabkan kesalahan dalam sistem manual. Dalam beberapa kasus lain, lembar kehadiran mungkin hilang atau dicuri oleh beberapa mahasiswa. Konsekuensi dari masalah tersebut dengan daftar hadir berbasis kertas telah membuatnya masalah dan tidak efektif, terutama di kelas besar. Untuk itu, dalam kajian ini dibuat sebuah sistem dengan cara baru dalam absensi kehadiran mahamahasiswa di kelas di perguruan tinggi untuk pembelajaran akademik yang lebih efisien dan efektif.

Oleh karena itu, sangat penting untuk mengembangkan sistem kehadiran yang dilengkapi dengan basis data secara online, terutama untuk mencegah kehilangan data serta untuk mempromosikan dalam kampanye tanpa kertas dan teknologi hijau serta kampanye lingkungan. Selain itu, aplikasi ini akan membantu mengurangi waktu yang terbuang, yang mengarah pada produktivitas belajar yang lebih baik di kelas. Ada beberapa sistem absensi tanpa kertas yang telah dikembangkan tetapi sistem seperti itu harus dilengkapi dengan komputer atau pembaca RFID, yang mengakibatkan biaya tambahan untuk perangkat keras dan pemeliharaannya mungkin akan lebih mahal. Dengan penelitian ini, kami bertujuan untuk mengatasi masalah dengan merancang sistem dengan persyaratan perangkat keras minimal dan pada saat yang sama, meningkatkan aspek mobilitas dari sistem kehadiran yang ada. Selanjutnya, untuk mengatasi masalah seperti yang disebutkan dalam diskusi di atas, kita membutuhkan sistem manajemen kehadiran otomatis. Ada banyak metode yang tersedia di mana konsep dasarnya sama. Dalam sistem ini diusulkan sistem kehadiran mahamahasiswa dan staf (dosen) otomatis, di mana pembaca RFID dipasang di setiap ruang kelas dan ditugaskan dengan identitas untuk mengidentifikasi kelas yang digunakan.

\section{TINJAUAN PUSTAKA}

Pada bagian ini akan di bahas tentang beberapa penelitian yang telah dilakukan sebelumnya, beberapa karya sebelumnya meninjau sistem terkait dari mahamahasiswa berbeda untuk metode dalam mencatat kehadiran mahasiswa. Penggunaan sistem berbasis android untuk kehadiran mahasiswa sebagaimana dibahas dalam [1] aplikasi digunakan maka dapat mengunduh daftar mahamahasiswa dari web server yang disediakan. Merujuk ke daftar kehadiran mahamahasiswa di ruang kelas setelah memindai kartu ke pembaca Radio Frequency Identification (RFID) [2]. Perangkat tambahan seperti kamera yang digunakan untuk mendukung sistem informasi dan konfirmasi kehadiran mahamahasiswa. Penelitian lain membahas tentang sistem kehadiran yang diuraikan dalam [3] menggambarkan kehadiran mahamahasiswa tanpa campur tangan manusia. Penggunaan kamera sebagai metode tambahan di ruang kelas dan akan menangkap gambar ketika setiap mahasiswa masuk ke ruangan, wajah mahasiswa terdeteksi dan kemudian dikenali dan sesuaikan dengan data di database dan akhirnya kehadiran mahasiswa ditandai. Jika kehadiran ditandai sebagai tidak hadir, pesan tentang ketidakhadiran mahasiswa dikirimkan kepada orang tua mereka.

Penelitian lain dikembangkan sistem absensi mahasiswa menggunakan sebagian kecil dari kelas untuk poin partisipasi dan mengarahkan daftar kehadiran mahasiswa ke dalam sistem pengajaran yang telah ditentukan seperti kehadiran dengan memeriksa setiap mahasiswa, pengecekan 
secara acak berdasarkan daftar, dan kuis. Mirip dengan sistem peringkat tangga yang banyak digunakan dalam permainan komputer online saat ini, mahasiswa dapat memeriksa peringkat akumulasi ketidakhadiran dan poin di akhir kelas sebagai stimulus jangka panjang untuk belajar [4$6]$.

Sistem kehadiran mahasiswa secara konvensional mengharuskan secara fisik menandatangani lembar kehadiran setiap kali melakukan kuliah di kelas. Metode ini tidak perlu menghabiskan banyak waktu untuk memeriksa nama mahasiswa di lembar kehadiran. Banyak kejadian bahwa beberapa mahasiswa mungkin secara tidak sengaja menandatangani nama mahasiswa yang lain atau dengan sukarela melakukannya. Biasanya, lembar asli kehadiran setelah beberapa minggu mungkin hilang atau mudah berantakan. Penggunaan smartphone seperti teknologi android akan membantu guru untuk mendapatkan kehadiran mahasiswa dengan mudah melalui sistem online kemudian dapat memeriksa persentase mahasiswa yang menghadiri kelas juga untuk menyalin atau mencetaknya. Dengan menggunakan informasi yang tersimpan, guru dengan mudah menandai kehadiran mahasiswa, perhitungan persentase kehadiran, menandai entri penyusup, mengirim email atau mengirim pesan kepada orang tua agar mereka selalu mendapat informasi terbaru tentang kehadiran anak mereka di sekolah atau kampus $[7,8]$.

Prototipe sistem pendaftaran kehadiran kelas yang diaktifkan secara biometrik diuraikan oleh [9] pengembangkan dan rancangan untuk mengubah formulir pendaftaran absensi yang salah di berbagai ruang kelas di sekolah atau perguruan tinggi. Sistem menggunakan pembaca sidik jari biometrik untuk setiap mahasiswa sebelum masuk kelas. Seperti [9] membahas tentang sistem absensi mahasiswa menggunakan sistem Near Field Communication (NFC). Solusinya untuk menyediakan sistem absen pembelajaran kelas yang nyaman dan portabel untuk sekolah atau perguruan tinggi untuk meningkatkan interaksi dalam proses pembelajaran di antara mahasiswa dan mengurangi beban kerja dosen dalam memproses statistik kehadiran [10]. Seluruh penelitian sebelumnya menggunakan sistem online normal maka dalam penelitian ini mengusulkan metode baru sistem online untuk pasangan mahasiswa dan dosen untuk memastikan dosen hadir di kelas. Selain itu penggunaan cloud computing adalah salah satu fitur tambahan dalam sistem ini untuk memastikan data kehadiran mahasiswa dapat di akses oleh staf di mana-mana. Informasi kehadiran mahasiswa sangat penting tidak hanya untuk absensi kehadiran di kelas tetapi untuk bagian keuangan dalam pembayaran gaji dosen.

\section{PENGUSULAN SISTEM ABSENSI ONLINE}

Solusi yang diusulkan untuk sistem kehadiran mahasiswa secara online menggunakan beberapa komponen dan integrasi untuk menjadi sistem yang mampu mengelola kehadiran mahasiswa. Berbeda dengan sistem saat ini yang dikembangkan oleh peneliti lain, penggunaan cloud computing telah digunakan untuk sistem manajemen data di samping server lokal di bagian akademik. Gambar 1 menunjukkan blok diagram dari sistem absensi mahasiswa, di mana Arduino dan pembaca RFID adalah unit utama untuk sistem ini dalam mengontrol kehadiran mahasiswa dan staf.

Kartu mahasiswa dan karyawan dilengkapi dengan chip RFID yaitu Mifare 13,56 MHz dan memori $1 \mathrm{kB}$ sehingga dalam hal ini pengguna pembaca RFID untuk mengambil informasi mahasiswa atau staf dengan menggunakan sistem RFID. Informasi yang disimpan dalam kartu mahasiswa terbatas, hanya data identitas (ID) yang disimpan dengan beberapa informasi, sistem ini dirancang untuk mengambil informasi ID mahasiswa yang 9 karakter sama dengan nomor matrik mahasiswa, serta untuk ID staf dengan 9 karakter. Setelah ID mahasiswa atau staf diterima oleh pembaca RFID maka informasi yang diterima di Mikrokontroler Arduino dibandingkan dengan ID mahasiswa atau staf dalam database, dalam hal ini informasi mahasiswa terkait dengan sistem manajemen akademik mahasiswa, di mana setiap mahasiswa bertanggung jawab untuk tujuan akademik, karena data dan informasi yang tersedia maka sistem kehadiran hanya terhubung ke database tanpa membuat sistem manajemen database baru. Mirip dengan database mahasiswa, informasi kelas mahasiswa dan jadwal terkait dengan sistem manajemen akademik yang setiap fakultas harus mengelola jadwal kuliah di kelas, jadwal, subjek, waktu, dan pendaftaran mahasiswa subjek. 


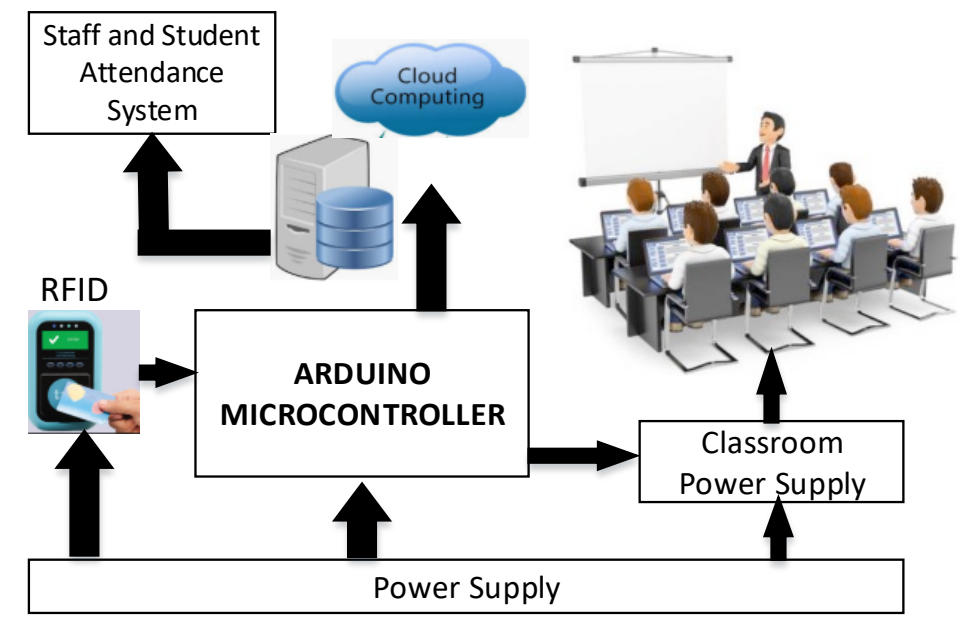

Gambar 1. Blok Diagram Sistem Kehadiran Secara Online

Gambar 2 menunjukkan diagram alur dari sistem absensi online yang digunakan dalam proses sistem ini. Semua informasi mulai dari pemindaian mahasiswa kartu kemudian sistem memutuskan apakah valid atau informasi untuk memproses atau tidak kemudian membuat keputusan kehadiran mahasiswa.

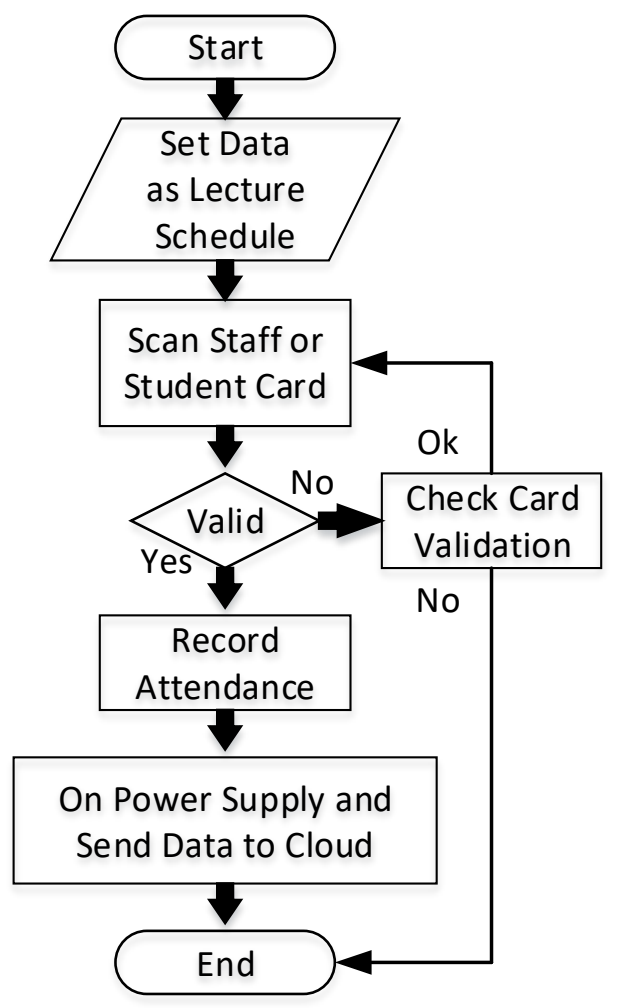

Gambar 2. Flowchart Sistem Kehadiran Online

\subsection{RFID}

Radio Frequency Identification (RFID) adalah teknologi berbasis komunikasi nirkabel dan Non-Line of Sight (NLOS) untuk mengambil informasi. Konsep dasar degan gelombang radio, RFID mampu mengumpulkan informasi dari transponder (tag) ke pembaca RFID, dengan keunggulan teknologi ini dan lebih nyaman untuk sistem kehadiran mahasiswa sehingga dapat diterapkan dalam 
sistem ini. Gambar 3 menunjukkan sampel kartu identitas mahasiswa yang digunakan dalam sistem ini dengan chip RFID yang ada di dalamnya.

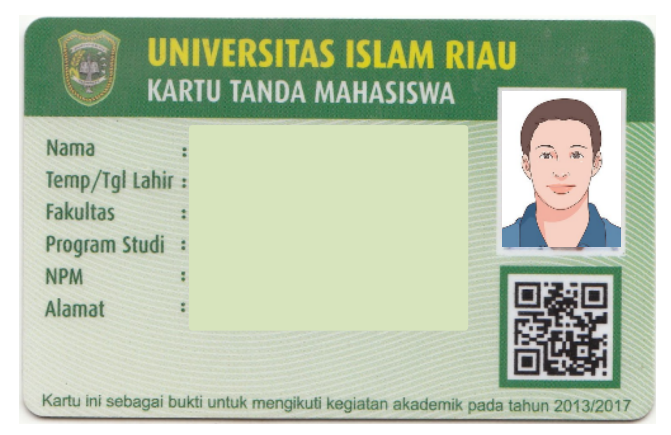

Gambar 3. Contoh Kartu Identitas Mahasiswa.

Sama dengan kartu identitas mahasiswa, setiap dosen dan karyawan dengan chip RFID di kartu identitasnya masing-masing, sehingga proses pengambilan data sama dengan kartu identitas mahasiswa. Gambar 4 menunjukkan contoh kartu tanda pengenal untuk dosen dan karyawan dengan chip RFID yang tertanam di dalamnya.

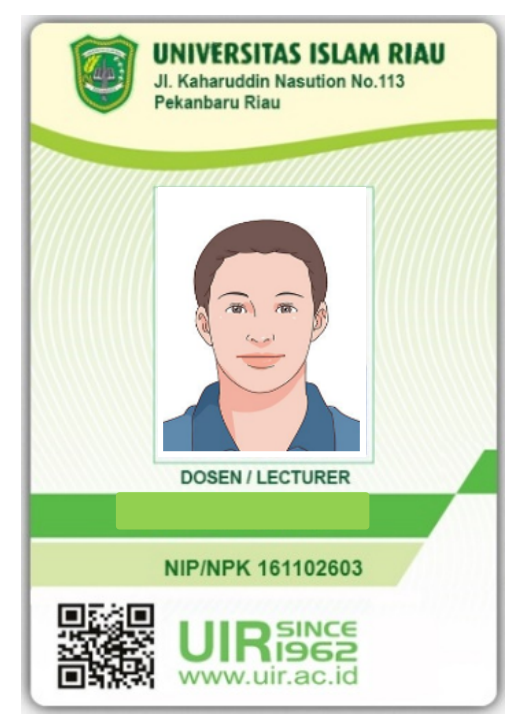

Gambar 4. Contoh Kartu Identitas Dosen.

\subsection{Arduino}

Arduino adalah sebuah sistem berbasis open source yang mudah digunakan oleh pengembang, perangkat keras dan perangkat lunak Arduino terintegrasi yang dikembangkan dalam sebuah paket. Saat ini, modul Arduino sudah digunakan di banyak aplikasi, sehingga dalam sistem absensi ini digunakan Arduino untuk sistem mikrokontroler. Gambar 5 menunjukkan gambar modul Arduino yang terhubung ke pembaca RFID untuk membaca dan mengambil informasi kartu identitas. Semua analisis informasi dan untuk dicocokkan dengan database serta jadwal kelas dan verifikasi kemudian informasi akhir disimpan dalam database. Agar dapat diakses oleh pihak mana pun yang membutuhkan informasi ini maka pengaturan basis data di cloud dalam menyimpan semua informasi tersebut. 


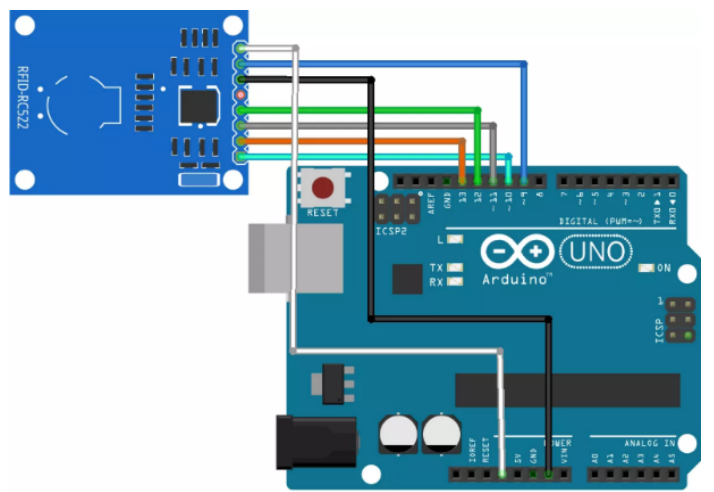

Gambar 5. Module Arduino Dengan Pembaca RFID

\subsection{Cloud Computing}

Cloud computing adalah teknologi dalam ilmu komputer yang baru-baru ini menjadi alternatif untuk perubahan data dari server lokal ke cloud. Permintaan untuk ketersediaan dalam sumber daya sistem komputer dan terutama untuk penyimpanan data dan sistem daya komputasi tanpa langsung ke server lokal yang dikelola oleh pengguna. Istilah cloud computing umumnya digunakan untuk menggambarkan pusat data yang tersedia bagi banyak pengguna melalui akses internet. Gambar 6 menunjukkan konfigurasi komputasi awan untuk diakses oleh pengguna dan sistem manajemen.

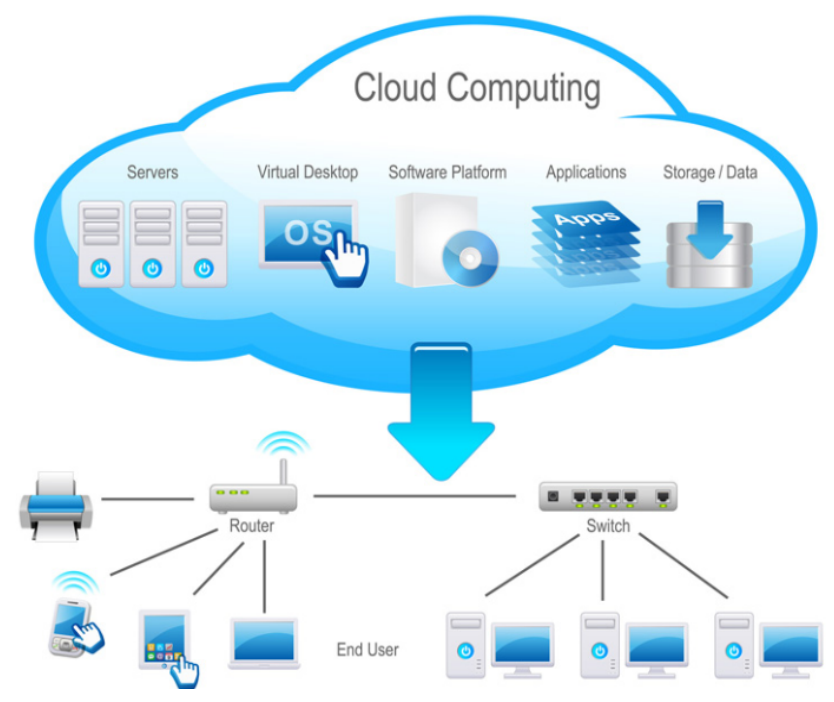

Gambar 6. Konfigurasi sebuah cloud computing.

\section{HASIL DAN PEMBAHASAN}

Penerapan sistem absensi mahasiswa telah dikembangkan dan diuji di kelas pada waktu perkuliahan, beberapa waktu kuliah diuji dengan sistem ini. Gambar 7 menunjukkan tampilan layar sistem kehadiran mahasiswa dan dosen di dalam kelas. 


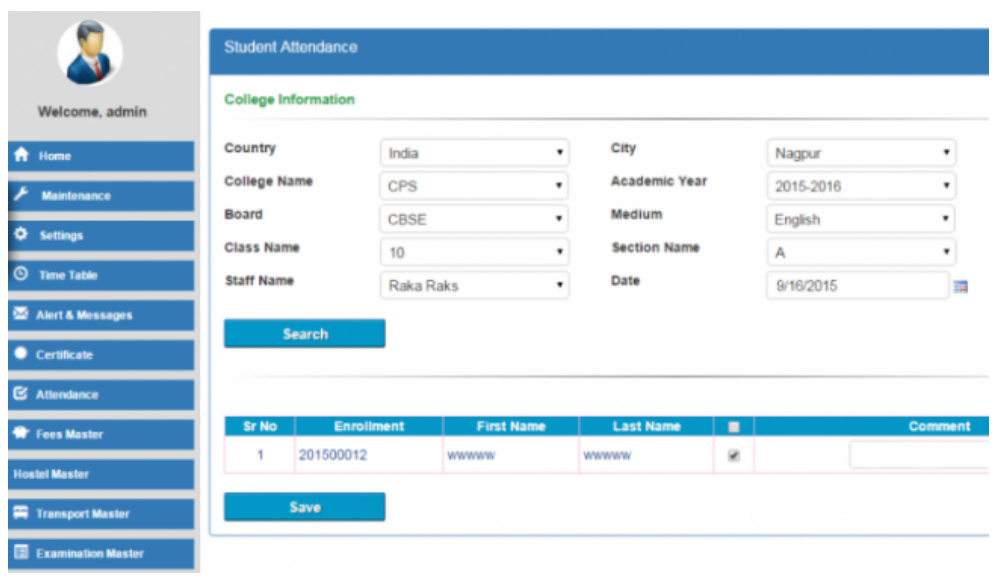

Gambar 7. Aplikasi Sistem Kehadiran Secara Online.

Dalam hal ini, rata-rata mahasiswa di kelas adalah 30 sampai dengan 40 mahasiswa, dimana mahasiswa sebelumnya menggunakan formulir lembar manual yang harus di tanda tangani untuk bukti kehadiran di kelas pada waktu kuliah, dengan aplikasi ini mahasiswa hanya menempelkan kartu identitas ke pembaca RFID yang dipasang di depan kelas. Setelah mahasiswa menempelkan kartu, jika status mahasiswa telah sesuai dengan jadwal kelas dan ruang kelas maka informasi direkam dan dikirim ke pusat data, dalam hal ini, komputasi awan digunakan untuk menyimpan semua informasi. Toleransi maksimum untuk yang terlambat di kelas adalah 15 menit, jadi setelah durasi yang terlambat mahasiswa dianggap tidak hadir meskipun mereka menempelkan kartu identitas di pembaca RFID, oleh itu dengan tidak ada catatan yang disimpan dalam database. Sama seperti dengan durasi toleransi yang terlambat, mahasiswa harus menempelkan kartu identitas untuk pembaca RFID sebelum kelas selesai untuk mencatat kehadiran waktu keluar, dalam hal ini, durasi adalah 15 sebelum jadwal waktu dan 10 menit setelah jadwal bahwa setiap mahasiswa harus menempelkan kartu untuk tanda keluar kelas agar bias direkam, jika mahasiswa hanya menempelkan hanya satu kali saja maka absensi dianggap tidak lengkap. Gambar 8 menunjukkan sistem untuk manajemen sebelum kelas mulai harus ditetapkan oleh petugas.

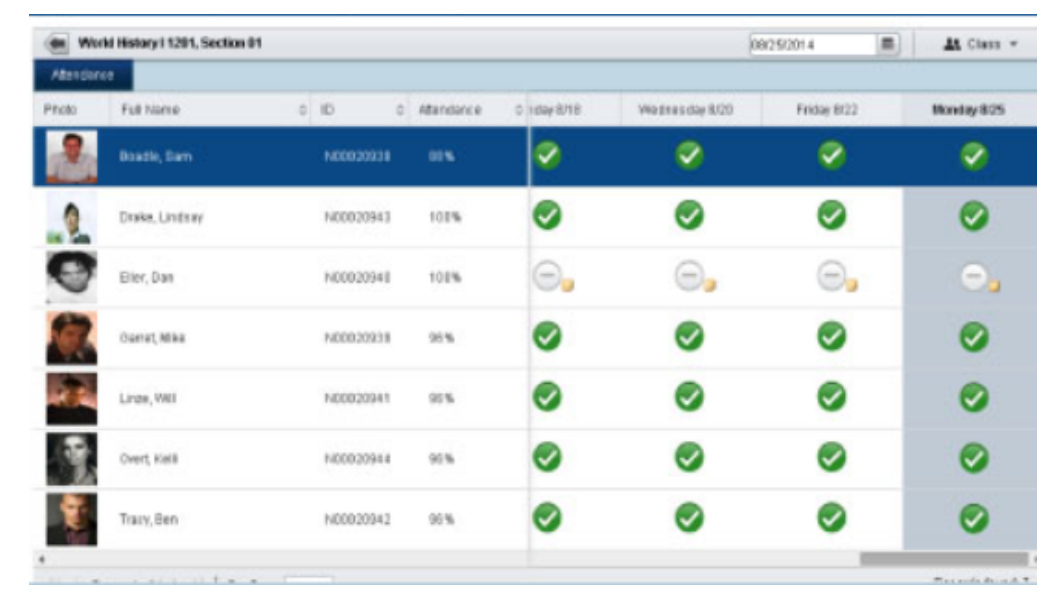

Gambar 8. Jadwal Sistem Kehadiran Absensi.

Laporan sistem kehadiran mahasiswa dihasilkan setelah perkuliahan selesai, laporan menunjukkan untuk setiap mahasiswa di kelas yang menghadiri mata pelajaran yang dilakukan oleh dosen. Laporan ini juga mencatat kehadiran untuk semua minggu, dalam hal ini 16 minggu untuk menyelesaikan satu mata kuliah penuh dalam satu semester. Gambar 9 menunjukkan lembar laporan yang dihasilkan oleh sistem ini. 


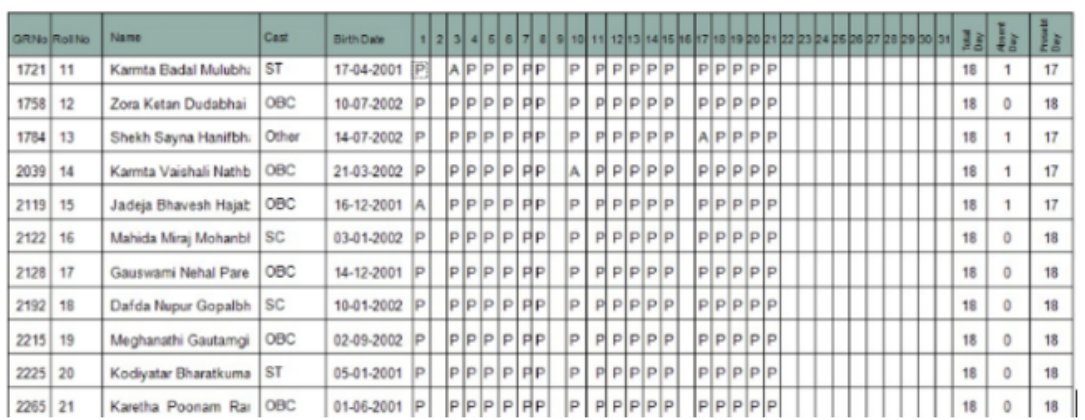

Gambar 9. Laporan Kehadiran Mahasiswa.

Semua informasi untuk setiap mahasiswa dan ruang kelas termasuk karyawan atau dosen dalam melakukan perkuliahan di ruang kelas yang dikirim ke sistem manajemen basis data terintegrasi, database pusat akan mengelola akun mahasiswa dan sistem penggajian untuk dosen, sistem ini membantu dalam manajemen untuk menghitung jam setiap dosen dalam sebulan dan jumlah honor yang akan di bayarkan. Informasi tentang catatan kehadiran mahasiswa dalam komputasi awan, maka pengembangan selanjutnya adalah membuat sistem mobile untuk laporan kepada orang tua atau wali.

\section{KESIMPULAN}

Sistem absensi mahasiswa sangat membantu bagi lembaga akademik, sebelumnya menggunakan sistem manual yang menimbulkan banyak masalah dan susah di kendalikan dalam hal kecurangan oleh mahasiswa. Sistem ini sudah diuji di beberapa kelas kuliah, dari 38 mahasiswa yang terdaftar di kelas dimana 36 mahasiswa hadir di kelas dan 2 mahasiswa tidak tercatat untuk pengujian pertama, dilanjutkan hingga 4 minggu. Sistem ini berhasil mencatat semua mahasiswa dan kehadiran kuliah kemudian merekam dalam database. Sistem ini dapat membantu petugas dan sistem yang sangat efisien, karyawan dan manajemen hanya memverifikasi jadwal perkuliahan di kelas kemudian konfirmasi sebelum catatan akhir. Cloud computing digunakan sebagai basis data untuk memudahkan pengambilan data dari pihak lain.

\section{UCAPAN TERIMA KASIH}

Penulis mengucapkan terima kasih kepada RISTEKDIKTI yang telah mendanai penelitian ini dan Universitas Islam Riau, Indonesia atas dukungan fasilitasnya.

\section{DAFTAR PUSTAKA}

[1] S. A. M. Noor, N. Zaini, M. F. A. Latip, and N. Hamzah, "Android-based attendance management system," in 2015 IEEE Conference on Systems, Process and Control (ICSPC), 2015, pp. 118-122.

[2] Evizal, T. A. Rahman, and S. K. A. A. Rahim, "Active RFID Technology for Asset Tracking and Management System," TELKOMNIKA, vol. 11, no. 1, pp. 137-146, 2013.

[3] E. Varadharajan, R. Dharani, S. Jeevitha, B. Kavinmathi, and S. Hemalatha, "Automatic attendance management system using face detection," in 2016 Online International Conference on Green Engineering and Technologies (IC-GET), 2016, pp. 1-3.

[4] S. Xiao, W. Liang, and Y. Tang, "Classroom Attention Restoration Using Computer Game Rewarding Mechanism," in 2018 13th International Conference on Computer Science \& Education (ICCSE), 2018, pp. 1-6.

[5] H. Gunawan and E. A. Kadir, "Integration protocol student academic information to campus RFID gate pass system," in 2017 4th International Conference on Electrical Engineering, Computer Science and Informatics (EECSI), 2017, pp. 1-6.

[6] P. Dębiec, "Effective Learner-Centered Approach for Teaching an Introductory Digital Systems Course," IEEE Transactions on Education, vol. 61, no. 1, pp. 38-45, 2018. 
[7] M. M. Islam, M. K. Hasan, M. M. Billah, and M. M. Uddin, "Development of smartphonebased student attendance system," in 2017 IEEE Region 10 Humanitarian Technology Conference (R10-HTC), 2017, pp. 230-233.

[8] W. T. Tarimo and T. J. Hickey, "Fully integrating remote students into a traditional classroom using live-streaming and TeachBack," in 2016 IEEE Frontiers in Education Conference (FIE), 2016, pp. 1-8.

[9] K. C. Wei, M. M. Singh, and H. M. B. Osman, "Near Field Communication Interactive Learning System (NILES) for Blended Learning: A Pervasive Social Networking Services," in 2017 Palestinian International Conference on Information and Communication Technology (PICICT), 2017, pp. 71-77.

[10] E. A. Kadir, S. L. Rosa, and H. Gunawan, "Application of RFID technology and e-seal in container terminal process," in 2016 4th International Conference on Information and Communication Technology (ICoICT), 2016, pp. 1-6.

\section{BIOGRAFI PENULIS}

\begin{tabular}{|l|l|} 
Sri Listia Rosa obtained Bachelor Degree in Electrical Engineering from Universitas Bung Hatta \\
Padang and obtained Master Degree in Computer Science and Information System from Universiti \\
Teknologi Malaysia in 2013. She has been a Lecturer with the Department of Informatics \\
Engineering, University Islam Riau, since 2015. Her current research interests include \\
computational intteligent, computional intelligent and machine learning.
\end{tabular} \mid $\begin{aligned} & \text { Evizal Abdul Kadir received his Master of Engineering and PhD in Wireless Communication at } \\
& \text { Faculty of Electrical Engineering, Universiti Teknologi Malaysia in 2008 and 2014 respectively. } \\
& \text { He is currently as Lecturer and Researcher in Islamic University of Riau (UIR) Indonesia as well } \\
& \text { as Director of research institute and community services and get promoted to Associate Professor. } \\
& \text { He has experience and worked in several companies that provide system solution in Wireless } \\
& \text { Communication and Radio Frequency (RF) as well as Radio Frequency Identification (RFID), } \\
& \text { currently is continuing his research activities related to the Wireless Communication System, } \\
& \text { Antenna, Remote Sensing, Radio Frequency Identification (RFID), Wireless Sensor Network } \\
& \text { (WSN), Wireless and Mobile Monitoring System and IoT. }\end{aligned}$

